\title{
Prevalence of non-reporting of hospital medical errors in the Islamic Republic of Iran
}

\author{
Mehrdad Askarian, ${ }^{1}$ Seyyed M. Sherafat, ${ }^{2}$ Maryam Ghodsi, ${ }^{3}$ Zahra Shayan, ${ }^{4}$ Charles Palenik, ${ }^{5}$ Nahid Hatam ${ }^{6}$ and Yavor Enchev ${ }^{7}$
}

${ }^{1}$ Department of Community Medicine, School of Medicine, Shiraz University of Medical Sciences, Shiraz, Islamic Republic of Iran; Health Behavior Science Research Center, Shiraz University of Medical Sciences, Shiraz, Islamic Republic of Iran. ${ }^{4}$ Trauma Research Center, Department of Community Medicine; ${ }^{2}$ Student Research Committee; ${ }^{6}$ Department of Health Service Administration, School of Management and Information Sciences, Shiraz University of Medical Sciences, Shiraz, Islamic Republic of Iran (Correspondence to: Mehrdad Askarian: askariam@sums.ac.ir). ${ }^{3}$ Shiraz University of Medical Sciences, Shiraz, Islamic Republic of Iran. ${ }^{5}$ School of Dentistry, Indiana University, Indianapolis, United States of America. Shiraz University of Medical Sciences, Shiraz, Islamic Republic of Iran. ${ }^{7}$ Department of Neurosurgery, University Hospital St. Marina, Medical University of Varna, Varna, Bulgaria..

\begin{abstract}
Background: Medical errors frequently occur in health care facilities, jeopardizing patient safety and increasing associated costs.

Aims: This cross-sectional investigation examined the rates of and reasons for non-reporting of medical errors at Nemazee Hospital, Shiraz, Islamic Republic of Iran.

Methods: Self-administered questionnaires were completed by 283 staff members, including physicians, nurses and medical students. One-way analysis of variance, Fisher's least significant difference post hoc, Spearman correlation coefficient and intraclass correlation tests were used for statistical analyses.

Results: Almost all (95.8\%) participants had observed at least 1 medical error during the previous year, with over half (50.5\%) observing 3-10 errors. The preferred method for reporting medical errors among physicians and medical students was verbal and informal (40.3\% and $41.8 \%$ respectively), while nurses preferred written forms $(45.7 \%)$. The results indicated significant differences between groups concerning individual and organizational barriers in general, and among all sub-categories $(P<0.001)$.
\end{abstract}

Conclusion: Concerns of legal entanglements and confidentiality issues were recognized as the main barriers to reporting medical errors.

Keywords: medical errors, non-reporting, patient safety, hospitals, health care workers

Citation: Askarian M; Sherafat SM; Ghodsi M; Shayan Z; Palenik C; Hatam N; et al. Prevalence of non-reporting of hospital medical errors in the Islamic Republic of Iran. East Mediterr Health J. 2020;26(11):1339-1346. https://doi.org/10.26719/emhj.19.050

Received: 20/06/17; accepted: 30/07/18

Copyright (C) World Health Organization (WHO) 2020. Open Access. Some rights reserved. This work is available under the CC BY-NC-SA 3.0 IGO license (https://creativecommons.org/licenses/by-nc-sa/3.o/igo)

\section{Introduction}

More than 16 years after the landmark report by the Institute of Medicine, serious concerns about patient safety continue to exist (1-3). Medical errors are estimated to be the third leading cause of death in the United States of America (4). There have been 4 major studies conducted since the Institute of Medicine study concerning deaths associated with medical errors. Together they cover over 37 million patient admissions with a $3.1 \%$ rate of adverse events and a $0.7 \%$ mortality rate (5-7).

Efficiency, security of care, care giver reactivity and patient contentment are safety parameters that are at the core of health care quality (3). The most crucial factor, however, is a comprehensive understanding of medical errors (8). Gathering meticulous evidence via transparent incident reporting, free sharing of data and the creation of a culture of learning from our mistakes are indispensable in the development of medical error reduction plans and improving patient safety $(2,5,9)$. The backbone of the movement towards an enhanced culture of safety is a well-organized error reporting system (10).
A survey in 6 South Australian hospitals reported that even though $98.3 \%$ of respondents were aware of their facility's incident reporting systems, more than $40 \%$ had never filed a report (11). Another study reported $84.3 \%$ of 338 internal medicine physicians and residents believed that reporting medical errors improved quality. However, their rate for reporting minor errors was only $16.9 \%$ and for major errors $3.8 \%(12)$. Understanding the multiple factors that influence reporting errors among health care workers is crucial to supplying missing elements of an effective communication programme. Such barriers can damage the transparency of a safety climate and a culture of learning from errors $(8,13,14)$.

A perfectionist belief is that only poor physicians make mistakes $(2,13)$. Several studies indicate that there is a lack of knowledge concerning reportable incidences. Many physicians and nurses often do not consider near misses and medication omissions as being reportable (2). In one study, $25 \%$ of participants did not know how to retrieve their facility's incident reporting form (11).

At the institutional level, the safety climate often determines front-line provider attitudes (13). Loss of 
malpractice insurance coverage, fear of punitive actions, time constraints, poorly designed reporting systems, negative feedback, lack of confidentiality and a power hierarchy within professional groups are factors that negatively affect error reporting $(2,8,13,14)$. Other factors can be even more specific, such as fear of disciplinary action and threats to positive evaluations and promotion, especially among nurses $(2,13,15)$.

In a study of 20 hospitals in the north of the Islamic Republic of Iran, 182 (0.06\% of 317966 admissions) medical errors were reported. The lack of a reliable reporting system, negative attitudes toward reporting among staff and managers and a punitive culture were mentioned as the potential causes (16). The rate of non-reporting was estimated at $78.9 \%$ within the nursing staff of a teaching hospital in Kermanshah (17). There were comparable results in 2 other independent surveys among nurses at Imam Khomeini Hospital in Tehran $(18,19)$.

Barriers to medical error reporting were investigated among health care providers in the Islamic Republic of Iran in 2012. The study reported a high incidence of mishaps with lower rates of reporting $(<50 \%)$. The absence of an effective medical error reporting system, an insufficient supporting atmosphere among peers, lack of sufficient knowledge regarding the importance of error reporting and fear of malpractice litigation were listed as the most common impediments (20).

In the summer of 2014, a web-based error reporting system was launched at Nemazee Hospital in Shiraz. Reporting forms were revised and multiple training courses presented. Following these efforts, error reports increased by approximately 2000 cases per month. However, topical specialists felt that there was still room for improvement. Also, there was a strong need to compare the effectiveness of the Nemazee Hospital programme with others currently operating in the Islamic Republic of Iran. Therefore, the aims of this study were to determine the reasons behind non-reporting by hospital staff physicians, nurses and medical students and how well the facility error reporting is actually operating.

\section{Methods}

\section{Study setting}

We conducted a cross-sectional descriptive study from September-December 2015 in Nemazee Hospital, Shiraz, Islamic Republic of Iran. The facility is a general, specialty and subspecialty teaching hospital with 750 beds and is considered as the main referral centre in the south of the country.

\section{Questionnaires}

Data were collected from 283 participants (82\% response rate), including physicians, nurses and medical students using a self-administered questionnaire. Samples were selected with a confidence level of $95 \%$, standard deviation 2 (score of barriers against error reporting based on a pilot study), precision of 0.25 , population of 2000 and considering withdrawal proportion of $25 \%$.

The study population was selected randomly from available personnel in all 32 wards in the hospital and during all shifts. Questionnaires were presented in written form and completed immediately during a break in the shift and took 10 minutes on average. The questionnaire used in this study was developed by a hospital study group. A group of topical experts then assessed the questionnaire for content validity. The questionnaire was piloted on 19 medical students and 17 nurses in the study group. Cronbach's alpha calculation was used to assess reliability. The resulting value was 0.819 .

The first section of the questionnaire covered demographic characteristics, including sex, work experience and department. The second section contained questions about participant knowledge concerning medical errors, past in-service training, number of witnessed errors during the previous year, preferred method for reporting errors and response to medical errors committed, either by themselves or their peers.

Barriers to medical error reporting were assessed through 13 statements involving personal and organizational opinions and behaviours. Participants reported their level of agreement using a scale of 1-10. Unfamiliarity with medical errors or the reporting process, fear of punishment, cultural issues within a group, lack of confidentiality, a time-consuming reporting system, lack of proper feedback and fear of malpractice lawsuits were considered as organizational factors. There were 4 additional questions that addressed respondent knowledge about medical errors.

\section{Statistical analyses}

Analysis included descriptive analysis, 1-way analysis of variance, Fisher's least significant difference post hoc, intraclass correlation (ICC) test. SPSS, version 23, was used. $P$-value $<0.05$ was considered significant.

\section{Ethical considerations}

The protocol of this study was approved by the Shiraz University of Medical Sciences research ethics committee (IR.SUMS.MED.REC.1394.So1). Participation was voluntary.

\section{Results}

Participants included 151 nurses (53.3\%), 77 physicians (27.2\%) and 55 medical students (19.4\%). The largest group of participants [53 nurses (35.1\%), 41 physicians $(53.2 \%)$ and 23 medical students (41.8\%)] worked in internal medicine units; 62 nurses (41.1\%) and 31 physicians $(40.2 \%)$ had less than 5 years of work experience. Witnessing at least 1 error during the previous year was reported by 271 (95.5\%) respondents. More than half $(143,50.5 \%)$ had observed 3-10 medical errors in the previous year (Table 1). 
Table 1 Distribution of observed medical errors among physicians, nurses and medical students $(n=283)$ during 2015 in Nemazee Hospital, Shiraz , Islamic Republic of Iran

\begin{tabular}{lcccc} 
Occupation & \multicolumn{2}{c}{ No. of times seen } \\
& Not seen (\%) & $\mathbf{1 - 2}(\%)$ & $\mathbf{3 - 1 0}(\%)$ & \multicolumn{1}{c}{$\mathbf{1 0}(\%)$} \\
\hline Physician & 1.3 & 23.4 & 54.5 & 20.8 \\
Nurse & 7.3 & 31.1 & 45.0 & 16.6 \\
Medical student & 0.0 & 20.0 & 60.0 & 20.0 \\
Total & 4.2 & 26.9 & 50.5 & 18.4 \\
\hline
\end{tabular}

Physicians ( $n=31,40.3 \%)$ and medical students $(n=23$, $41.8 \%$ ) preferred to report errors via a telephone call or in person to a supervisor. However, nurses favoured using written forms to report an error $(n=69,45.7 \%)$.

Among physicians, 32 (41.6\%) stated that "they would report only themselves, believing reporting superiors would be considered offensive." Among nurses, 54 (35.8\%) believed that "It is mandatory to report all witnessed errors to a supervisor". The largest group of medical students $(n=21,38.2 \%)$ indicated that "It is mandatory to disclose if the committed error is significant (e.g. vitally important)".

Knowing the person making an error would not influence the decision to report for 38 physicians (49.4\%), 120 nurses (79.5\%) and 31 medical students (56.4\%). To measure agreement of actual information level and the self-perception of participants, we calculated group ICC indices: most correlations were weak. The degree of consistency among physicians (ICC $=0.06$ ) was less than for nurses $($ ICC $=0.39)$ and medical students $($ ICC $=0.38)$.

The questionnaire also assessed the impact that hospital-provided medical error training courses had on study participants; 55 physicians (71.4\%) and 24 medical students $(43.6 \%)$ reported having no or inadequate training on errors $(n=59,76.6 \%)$ and error reporting ( $n=39,70.9 \%$ ). Conversely, most nurses reported that they had received adequate training on error identification ( $n=89,58.9 \%)$ and error reporting $(n=98,64.9 \%)$.

The second part of the questionnaire contained 13 statements regarding possible obstacles to error reporting. The analysis of variance test indicated significant differences between groups concerning individual barriers in general and among all subcategories, with nurses having the highest mean score for all categories (Table 2). The least significant difference post-hoc analysis showed statistically significant differences between nurses and physicians $(P<0.001)$ and nurses and medical students $(P<0.001)$. Similarly, significant differences existed among the 3 study groups concerning organizational barriers in general and among all sub-categories (again, nurses had the highest mean score in each category) (Table 3).

Barriers most often mentioned by physicians were "Worrying about the revelation of a colleague's identity",

\begin{tabular}{|c|c|c|c|}
\hline Barrier & Mean (range 0-5) & SD & P-value \\
\hline \multicolumn{4}{|l|}{ Individual (overall) } \\
\hline Physicians & 1.8 & 0.4 & \multirow[t]{3}{*}{$<0.001$} \\
\hline Nurses & 3.6 & 1.7 & \\
\hline Medical students & 1.9 & 0.3 & \\
\hline \multicolumn{4}{|c|}{ Unfamiliarity with medical error/reporting process } \\
\hline Physicians & 1.7 & 0.5 & \multirow[t]{3}{*}{$<0.001$} \\
\hline Nurses & 3.1 & 1.9 & \\
\hline Medical students & 1.8 & 0.5 & \\
\hline \multicolumn{4}{|l|}{ Fear of punishment } \\
\hline Physicians & 2.1 & 0.7 & \multirow[t]{3}{*}{$<0.001$} \\
\hline Nurses & 4.6 & 3.0 & \\
\hline Medical students & 2.3 & 0.6 & \\
\hline \multicolumn{4}{|l|}{ Cultural issues } \\
\hline Physicians & 1.6 & 0.5 & \multirow[t]{3}{*}{$<0.001$} \\
\hline Nurses & 3.2 & 1.9 & \\
\hline Medical students & 1.5 & 0.4 & \\
\hline
\end{tabular}

P-value is estimated based on 1-way analysis of variance test.

$S D=$ standard deviation. 


\begin{tabular}{|c|c|c|c|}
\hline Barrier & Mean & SD & $P$-value \\
\hline \multicolumn{4}{|c|}{ Organizational (overall) } \\
\hline Physicians & 2.1 & 0.5 & \multirow[t]{3}{*}{$<0.001$} \\
\hline Nurses & 4.4 & 2.2 & \\
\hline Medical students & 2.1 & 0.4 & \\
\hline \multicolumn{4}{|l|}{ No confidentiality } \\
\hline Physicians & 2.0 & 0.7 & \multirow[t]{3}{*}{$<0.001$} \\
\hline Nurses & 4.1 & 3.1 & \\
\hline Medical students & 2.0 & 0.7 & \\
\hline \multicolumn{4}{|c|}{ Time consuming reporting system } \\
\hline Physicians & 2.0 & 0.8 & \multirow[t]{3}{*}{$<0.001$} \\
\hline Nurses & 4.3 & 3.1 & \\
\hline Medical students & 1.9 & 0.8 & \\
\hline \multicolumn{4}{|c|}{ Lack of proper feedback } \\
\hline Physicians & 2.2 & 0.8 & \multirow[t]{3}{*}{$<0.001$} \\
\hline Nurses & 4.5 & 2.2 & \\
\hline Medical students & 2.2 & 0.7 & \\
\hline \multicolumn{4}{|c|}{ Fear of malpractice lawsuit } \\
\hline Physicians & 2.2 & 0.8 & \multirow[t]{3}{*}{$<0.001$} \\
\hline Nurses & 4.7 & 3.4 & \\
\hline Medical students & 2.2 & 0.7 & \\
\hline
\end{tabular}

P-value is estimated based on 1-way analysis of variance test.

$\mathrm{SD}=$ standard deviation.

"Fear of a malpractice lawsuit" and "An inefficient error reporting system". The top issue for nurses and medical students was "Worry about being criticized by peers or supervisors" (Table 4).

\section{Discussion}

Medical errors remain a serious health concern worldwide and require special attention by health care administrators and policy-makers $(5,10)$. Health care providers are often reluctant to report patient safety problems, which could jeopardize proper medical error reporting (13). This study was designed to assess the main impediments against error reporting among physicians, nurses and medical students in Nemazee Hospital.

We found that almost $96 \%$ of respondents had observed an error at least once during the previous year. This agrees with an American study in which 94\% of physicians and $88.7 \%$ of other health care workers witnessed one or more medical errors in their department (12). The majority (98\%) of anaesthetists who participated in a similar study conducted in Switzerland disclosed being involved with a medical error (7).

As in other studies, we found that nurses were more inclined to report medical errors than were physicians and students. Physicians perceived more barriers against proper reporting $(21,22)$. One study indicated that only $42 \%$ of physicians routinely reported medical errors (23). Conversely, the findings of a Saudi Arabian study suggested physicians were more likely to report major medical errors than other health care workers (9). Our findings are comparable to surveys in that demographic characteristics, especially work experience and assigned wards among nurses, did not influence medical error reporting (13).

The informal reporting style of physicians has been noted in other studies $(9,14)$. Nurses favoured more formal reporting schemes for all types of errors. All 3 of our groups indicated their rate of reporting was the same if the error was theirs or that of a colleague. However, Alsafi et al. indicated that almost one-third of physicians would not report a peer to preserve their relationship (9).

In our study, the ranking of barriers was different between the groups. Fear of legal complaints, reproach, punishment, lack of positive feedback, concern for endangering a colleague's occupational status or revelation of his/her identity were often reported. In contrast, items such as "Errors are unavoidable in medical practice" and "There was nothing serious to report" received the lowest scores. However, a study from Australia reported conflicting results (24).

Fear of legal consequences was among the top reasons for non-reporting by physicians, nurses and medical students. Legal repercussions have been recognized as one of the most pervasive obstacles to open communication $(25,26)$. A study of 733 nurses in Urmia, Islamic Republic of Iran, indicated that reproach and penalties were the most cited obstacles to proper reporting (26). A survey among 


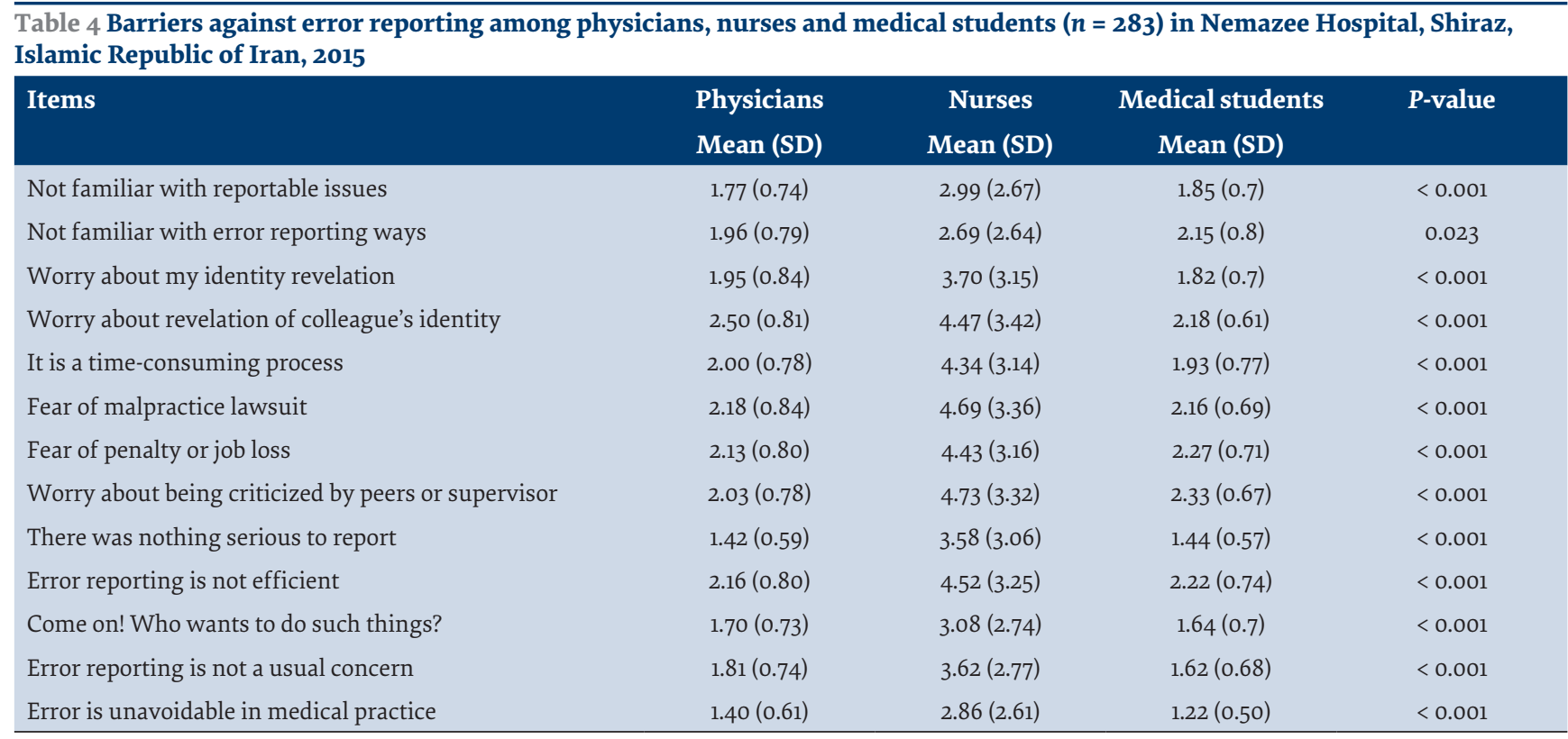

SD = standard deviation.

nurses from hospitals affiliated with Tehran and Shiraz universities of medical sciences listed fear of legal action, job threats and a negative culture of blame as major impediments (27). However, some studies, including one from the Netherlands, indicated that fear of legal complaints was not a significant concern for internists and residents reporting medical errors $(8,28)$.

Research carried out in the United States of America revealed that when anonymous reporting was established, nurses reported both minor and major medical errors at higher rates (29). In a Saudi Arabian study, $60 \%$ of physicians noted that reporting would be easier when there was a heightened level of confidentiality (9). Fear of being identified was not a major concern in our study, however, it was listed as one of the most discouraging factors concerning medical error reporting.

Time consumption was not a top-ranked factor against proper medical error in our study nor in another from the Islamic Republic of Iran (26). More than 50\% of Australian physicians and $40 \%$ of nurses felt their cumbersome reporting system was an important barrier (30). A Swiss cross-sectional survey involving anaesthetists reported not only sluggish reporting systems, but also inadequate feedback and lack of information negatively affected error reporting (8). Polisena et al. determined that more than half of the physicians and nurses surveyed believed their reporting system was incompetent and that they failed to receive plausible and timely feedback (30). Our study showed comparable results, which indicated that ineffectiveness of the error reporting system was among the top 3 causes of non-reporting by physicians, nurses and medical students.

The World Health Organization published a guideline for medical students in 2009 which included 11 topics on patient safety (31). A number of studies indicate that most medical students receive little information about medical errors or reporting techniques $(32,33)$, and staff physicians and nurses do not receive adequate information (8). Throckmorton et al. showed nurses could not identify errors in $40 \%$ of cases (29), although no practical scenario was provided for the accurate assessment of medical error recognition and understanding in this study, and there was evidence that $73.5 \%$ of nurses and almost half of physicians and medical students had an inadequate background on the topic.

Significant limitations of this study included voluntary participation, self-reporting of information and possible recall bias. Some participants might not have recalled their errors very well. This could result in underestimation of the actual rate of reported medical errors. Also, correlation measurements between causes of non-reporting and job titles of nurses, including supervisory, was not possible due to the limited number of supervisors and head nurses among our participants. Possible future studies could involve greater numbers of participants and other types of health care workers. Applying our questionnaire in other hospitals could also be worthwhile. It would be valuable if hospitals of various sizes were involved.

\section{Conclusions}

Concerns about legal entanglements, reporting methodology and confidentiality issues were recognized as the main barriers to reporting medical errors in Nemazee Hospital. Nurses did report errors at higher rates and they were found to prefer more formal, extensive, written reporting forms and the inclusion of all types of errors. Physicians and medical students preferred the opposite. Furthermore, the lack of knowledge on identifying and reporting medical errors among physicians and medical students requires attention by hospital administers. It appears that a formal reintroduction of the reporting system with accompanying in-service training is needed. 


\section{Acknowledgment}

This article is the result of a research project that was funded by the Vice-Chancellor for Research, Shiraz University of Medical Sciences, and carried out by Seyyed Mohammad Mahdi Sherafat in partial fulfilment of the requirements for certification as a general practitioner at Shiraz University of Medical Sciences.

Funding: Shiraz University of Medical Sciences, Grant No. 7696.

Competing interests: None declared.

\section{Prévalence de la non-notification des erreurs médicales en milieu hospitalier en République islamique d'Iran \\ Résumé}

Contexte : Les erreurs médicales sont fréquentes dans les établissements de soins, ce qui a pour effet de mettre en péril la sécurité des patients et d'augmenter les coûts associés.

Objectifs : La présente étude transversale avait pour objectif d'examiner les taux et les raisons de la non-notification des erreurs médicales à l'hôpital de Nemazee, à Chiraz en République islamique d'Iran.

Méthodes : Des questionnaires auto-administrés ont été remplis par 283 membres du personnel, parmi lesquels des médecins, des membres du personnel infirmier et des étudiants en médecine. Une analyse de variance à sens unique, le test post hoc de la différence la moins significative de Fisher, le coefficient de corrélation de Spearman et les tests de corrélation intraclasse ont été utilisés pour les analyses statistiques.

Résultats : La quasi-totalité des participants (95,8\%) avait observé au moins une erreur médicale au cours de l'année précédente, plus de la moitié (50,5\%) ayant relevé entre 3 et 10 erreurs. Pour signaler les erreurs médicales, les médecins et les étudiants en médecine privilégiaient la méthode verbale et informelle (40,3\% et 41,8\% respectivement), tandis que le personnel infirmier préférait les formulaires écrits (45,7\%). Les résultats indiquent des différences significatives entre les groupes concernant les obstacles individuels et organisationnels en général, et entre toutes les sous-catégories ( $p<0,001)$.

Conclusion : L'étude a montré que la complexité juridique et les problèmes de confidentialité constituaient les principaux obstacles à la notification des erreurs médicales.

$$
\text { معدل انتشار عدم الإبلاغ عن الأخطاء الطبية في المستشفيات في جمهورية إيران الإسلامية أسكريان، سيد شرافت، مريم قدسي، زهرة شايان، تشارلز بالينيك، ناهيد حاتم، يافور إنشيف }
$$

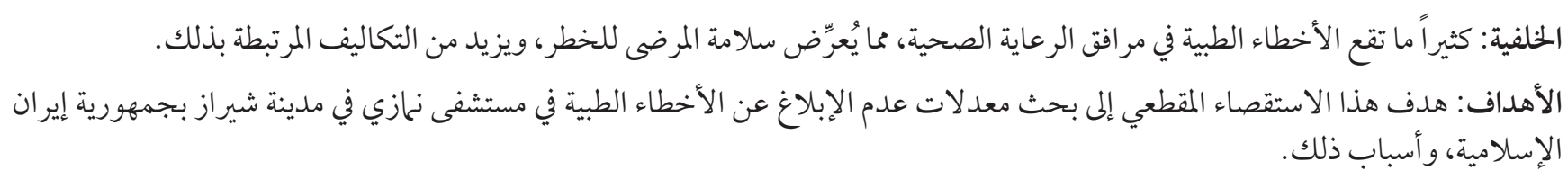

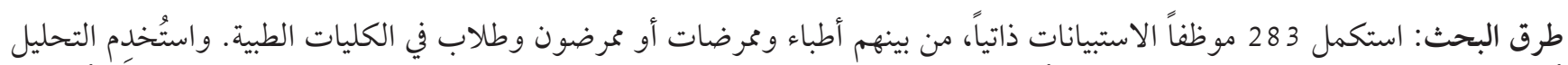

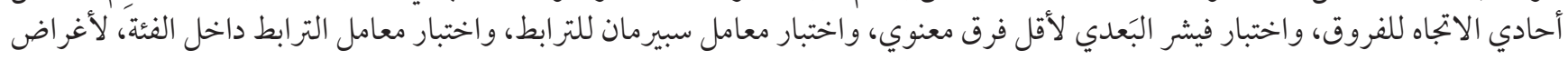
التحليلات الإحصائية.

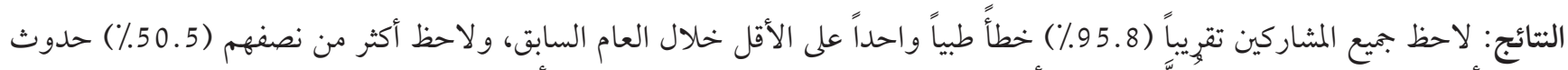

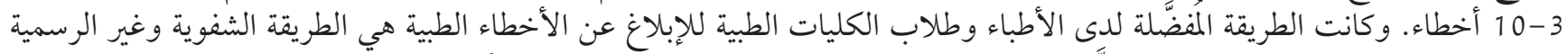

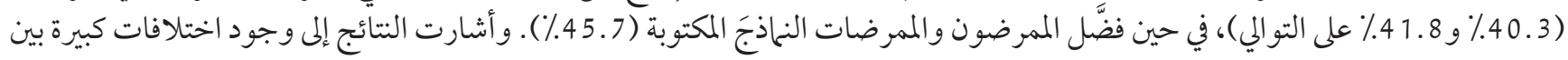

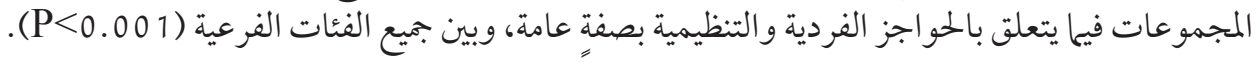
الاستنتاجات: ثُبت أن الشو اغل المتعلقة بالتشابكات القانونية وقضايا السرية هي العقبات الرئيسية التي تعترض الإبلاغ عن الأخطاء الطبية. 


\section{References}

1. Kohn LT, Corrigan JM, Donaldson MS. To err is human: building a safer health system. Washington, DC: National Academy Press; 1999.

2. Mahajan RP. Critical incident reporting and learning. Br J Anaesth. 2010 Jan;105(1):69-75. doi:10.1093/bja/aeq133. PMID:20551028

3. Garrouste-Orgeas M, Philippart F, Bruel C, Max A, Lau N, Misset B. Overview of medical errors and adverse events. Ann Intensive Care. 2012 Jan;2(1):2. doi:10.1186/2110-5820-2-2. PMID:22339769

4. Deaths: final data for 2013. National Vital Statistics Report. Atlanta: Centers for Disease Control and Prevention; (http:///www. cdc.gov/nchs/fastats/ leading-causes-of-death.htm, accessed 27 May 2018).

5. Makary MA, Daniel M. Medical error - the third leading cause of death in the US. BMJ. 2016 May;2139:1-5. doi:10.1136/bmj.i2139. PMID:27143499

6. James JT. A New, Evidence-based estimate of patient harms associated with hospital care. J Patient Safety. 2013 Sep;9(3):122-8. doi:10.1097/PTS.obo13e3182948a69. PMID:23860193

7. Wilson RM, Michel P, Olsen S, et al. Patient safety in developing countries: retrospective estimation of scale and nature of harm to patients in hospital. BMJ. 2012 Mar;344:e832. doi:10.1136/bmj.e832. PMID:22416061

8. McLennan SR, Engel-Glatter S, Meyer AH, Schwappach DLB, Scheidegger DH, Elger BS. Disclosing and reporting medical errors. Eur J Anaesthesiol. 2015 July;32(7):471-6. doi:10.1097/EJA.0000000000000236. PMID:26389547

9. Alsafi E, Bahroon SA, Tamim H, Al-Jahdali HH, Alzahrani S, Al Sayyari A. Physicians' attitudes toward reporting medical errors-an observational study at a general hospital in Saudi Arabia. J Patient Safety. 2011 Mar;7(3):143-6. doi:10.1097/PTS.0bo13e31822C5a82. PMID:21857239

10. Poorolajal J, Rezaie S, Aghighi N. Barriers to medical error reporting. Int J Prev Med. 2015 Oct 7;6:97. doi:10.4103/20087802.166680. PMID:26605018

11. Evans SM, Berry JG, Smith BJ, Esterman A, Selim P, O'Shaughnessy J, DeWit M. Attitudes and barriers to incident reporting: a collaborative hospital study. Qual Saf Health Care. 2006 Feb;15(1):39-43. doi:10.1136/qshc.2004.012559. PMID:16456208

12. Smith KS, Harris KM, Potters L Sharma R, Mutic S, Gay HA, Wright J, Samuels M, Ye X, Ford E, Terezakis S. Physician attitudes and practices related to voluntary error and near-miss reporting. J Oncol Pract. 2014 Sept;10(5):e350-7. doi:10.1200/ JOP.2013.001353. PMID:25095825

13. Castel ES, Ginsburg LR, Zaheer S, Tamim H. Understanding nurses' and physicians' fear of repercussions for reporting errors: clinician characteristics, organization demographics, or leadership factors? BMC Health Serv Res. 2015 Aug;15:326. doi:10.1186/ S12913-015-0987-9.PMID:26272228

14. Perez B, Knych S a, Weaver SJ, Liberman A, Abel EM, Oetjen D, Wan TT. Understanding the barriers to physician error reporting and disclosure: a systemic approach to a systemic problem. J Patient Saf. 2014 Mar;10(1):45-51. doi:10.1097/PTS. obo13e31829e4b68. PMID:24553443

15. Kaldjian LC, Jones EW, Rosenthal GE. Facilitating and impeding factors for physicians' error disclosure: A structured literature review. Jt Comm J Qual Patient Saf. 2006 Apr;32(4):188-98. PMID:16649649

16. Saravi B, Mardanshahi A, Ranjbar M, Siamian H, Azar MS, Asghari Z, Motamed N. Rate of Medical Errors in Affiliated Hospitals of Mazandaran University of Medical Sciences. Mater Socio Medica. 2015 Feb;27(1):31. doi:10.5455/msm.2014.27.31-4. PMID:25870528

17. Mirzaei M, Safari Faramani R, Sepahvand E. [Prevalence, types of medication errors and barriers to reporting errors by nursing in an educational hospital in Kermanshah]. Hayat. 2013 Mar;19(3):28-37 (in Farsi).

18. Cheraghi MA, Nikbakhat Nasabadi AR, Mohammad Nejad E, Salari A, Ehsani Kouhi Kheyli SR. Medication errors among nurses in intensive care units (ICU). J Mazand Univ Med Sci. 2012 Jan;22(Suppl. 1):115-9.

19. MohammadNejad E, Ehsani SR, Salari A. Sajjadi A, Hajiesmaeelpour A. Refusal in reporting medication errors from the perspective of nurses in emergency ward. J Res Dev Nurs Midwifery. 2013 Jan;10(1):61-8.

20. Pfeiffer Y, Briner M, Wehner T, Manser T. Motivational antecedents of incident reporting: Evidence from a survey of nurses and physicians. Swiss Med Wkly. 2013 Nov;143:1-11. doi:10.4414/smw.2013.13881 PMID:24222585

21. Kingston MJ, Evans SM, Smith BJ, Berry JG. Attitudes of doctors and nurses towards incident reporting: a qualitative analysis. Med J Aust. 2004 Jul;181(1):36-9. PMID:15233611

22. Zaheer S, Ginsburg L, Chuang Y-T, Grace SL. Patient safety climate (PSC) perceptions of frontline staff in acute care hospitals: Examining the role of ease of reporting, unit norms of openness, and participative leadership. Health Care Manage Rev. 2013 Jan-Mar;40(1):13-23. doi:10.1097/HMR.0000000000000005. PMID:24378403

23. Waring JJ. Beyond blame: cultural barriers to medical incident reporting. Soc Sci Med. 2005 May;60(9):1927-35. PMID:15743644

24. Iedema R, Allen S, Sorensen R, Gallagher TH. What prevents incident disclosure, and what can be done to promote it? Jt Comm J Qual Patient Saf. 2011 Sep;37:409-17. PMID:21995257

25. Heard GC, Sanderson PM, Thomas RD. Barriers to adverse event and error reporting in anesthesia. Anesth Anal. 2012 Mar;114:604-14. doi:10.1213/ANE.obo13e31822649e8. PMID:21821515 
26. Bayazidi S, Zarezadeh Y, Zamanzadeh V, Parvan K. Medication error reporting rate and its barriers and facilitators among nurses. J Caring Sci. 2012 Nov 27;1(4):231-6. doi:10.5681/jcs.2012.032. PMID:25276700

27. Hashemi F, Nasrabadi AN, Asghari F. Factors associated with reporting nursing errors in Iran: a qualitative study. BMC Nurs. 2012 Oct;11(1):20. doi:10.1186/1472-6955-11-20. PMID:23078517

28. Linthorst GE, Kallimanis-King BL, Douwes Dekker I, Hoekstra JB, de Haes JC. What contributes to internists' willingness to disclose medical errors? Neth J Med. 2012 Jun;70(5):242-8. PMID:22744929

29. Throckmorton T, Etchegaray J. Factors affecting incident reporting by registered nurses: the relationship of perceptions of the environment for reporting errors, knowledge of the nursing practice act, and demographics on intent to report errors. J Peri Anesth Nurs. 2007 Dec;22(6):400-12. PMID:18039512

30. Polisena J, Gagliardi A, Urbach D, Clifford T, Fiander M. Factors that influence the recognition, reporting, and resolution of incidents related to medical devices and other healthcare technologies: a systematic review. Syst Rev. 2015 Mar;4:37. doi:10.1186/ s13643-015-0028-0. PMID:25875375

31. WHO patient safety curriculum guide for medical schools. Geneva: World Health Organization; 2009] (http://www.who.int/ patientsafety/activities/technical/medical_curriculum/, accessed 18 September 2019)

32. Flin R, Patey R, Jackson J, Mearns K, Dissanayaka U. Year 1 medical undergraduates? Knowledge of and attitudes to medical error. Med Educ. 2009 Dec;43(12):1147-55. doi:10.1111/j.1365-2923.2009.03499.X

33. Li L, Duan Y, Chen P, Li J, Mao X, Barraclough BH, Zhang M. Knowledge, skills, and attitudes of medical students to patient safety: A cross-sectional pilot investigation in China. J Evid Based Med. 2012 Aug;5(3):124-33. doi:10.1111/j.1756-5391.2012.01187.x. PMID:23672219. 